\title{
Minimum Porosity Formation in Pressure Die Casting by Taguchi Method
}

\author{
Quang-Cherng Hsu and Anh Tuan Do \\ Department of Mechanical Engineering, National Kaohsiung University of Applied Sciences, 415 Chien-Kung Road, \\ 80778 Kaohsiung City, Taiwan
}

Correspondence should be addressed to Anh Tuan Do; 1099403120@kuas.edu.tw

Received 17 September 2013; Accepted 15 October 2013

Academic Editor: Teen-Hang Meen

Copyright (C) 2013 Q.-C. Hsu and A. T. Do. This is an open access article distributed under the Creative Commons Attribution License, which permits unrestricted use, distribution, and reproduction in any medium, provided the original work is properly cited.

\begin{abstract}
Die casting process is significantly used in the industry for its high productivity and less postmachining requirement. Due to light weight and good formability, aluminum die casting plays an important role in the production of transportation and vehicle components. In the current study of die casting for Automobile starter motor casing, the following issues are focused: shot piston simulation, defect analysis, and, finally, the use of the Taguchi multiquality analytical method to find the optimal parameters and factors to increase the aluminium ADC10 die casting quality and efficiency. Experiments were conducted by varying molten alloy temperature, die temperature, plunger velocities in the first and second stage, and multiplied pressure in the third stage using $\mathrm{L}_{27}$ orthogonal array of Taguchi method. After conducting a series of initial experiments in a controlled environment, significant factors for pressure die casting processes are selected to construct an appropriate multivariable linear regression analysis model for developing a robust performance for pressure die casting processes. The appropriate multivariable linear model is a useful and efficient method to find the optimal process conditions in pressure die casting associated with the minimum shrinkage porosity percent.
\end{abstract}

\section{Introduction}

High pressure die casting for nonferrous casting applications is increasingly used in the foundries today as an economically viable casting process. High pressure die casting (HPDC) process has been widely used to manufacture a large variety of products with high dimensional accuracy and productivities. It has a much faster production rate in comparison to other methods and it is an economical and efficient method for producing components with low surface roughness and high dimensional accuracy. All major aluminium automotive components can be processed with this technology.

High Pressure Die Casting process is rapid and depends on many factors. So, to capture the problem it requires a lot of time and experience including testing and simulation. The conventional trial and error based die design and process development is expensive and time consuming. Such a procedure also might lead to higher casting rejections. The HPDC castings production process has many defects, such as shrinkage porosity, misrun, cold-shut, blister, scab, hottear. Several previous studies of defects in aluminum alloy by the method of HPDC and disability solutions (Shen et al. 2007 [1], Dargusch et al. 2006 [2], Verran et al. 2006 [3], Mousavi Anijdan et al. 2006 [4], Tsoukalas et al. 2004, $2008[5,6])$. However, the study to optimize aluminum alloy casting process in the condition of production casting factory is essential. This study focused on analysis of shrinkage porosity defect with mold design and put into production casting by foundry factory conditions.

Shrinkage porosity is one of the most common defects leading to rejection of aluminium die casting, often only showing up after much value has been added to the casting via operations such as machining, polishing, and coating. The added value of the casting at the point of rejection can be very high. If you find out the causes and how to reduce the defects of castings will be of great significance in reducing the production cost of die casting. However, optimizing the conditions to render aluminium die castings of minimum 


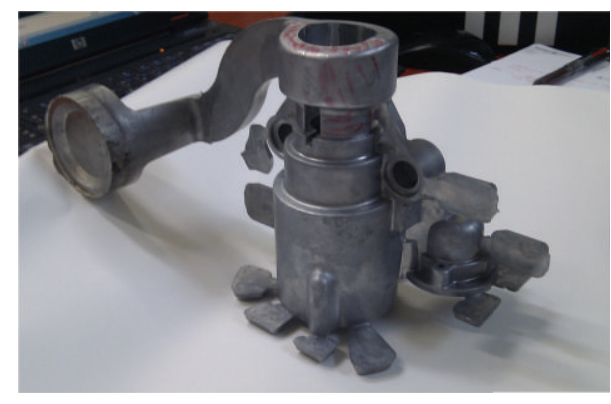

(a)

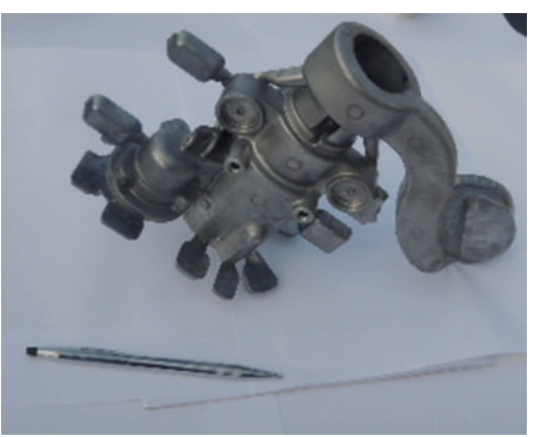

(c)

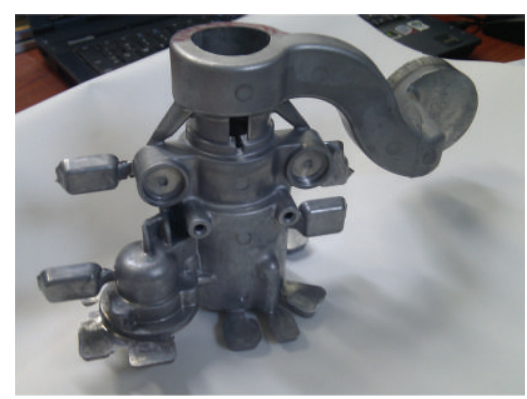

(b)

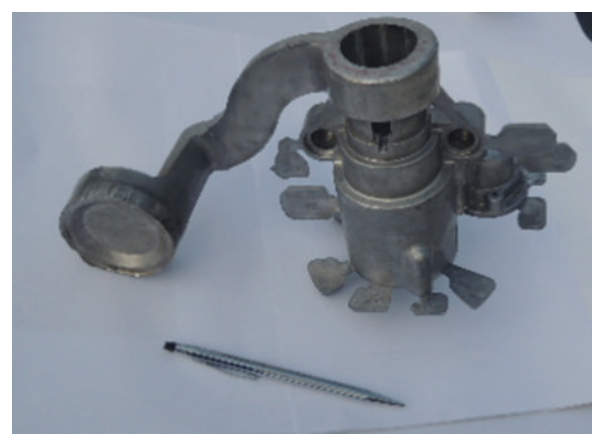

(d)

FIGURE 1: Casting image.

porosity percent is costly and time consuming, because many experiments are necessary to find the optimal parameters.

Taguchi method is one of the efficient problems solving tools to upgrade the performance of products and processes with a significant reduction in cost and time involved. Taguchi's parameter design offers a systematic approach for optimization of various parameters with regard to performance, quality, and cost (Syrcos 2003 [7], Taguchi 1986 [8]).

\section{Materials and Methods}

The die casting part product of this study is provided through aluminium die casting factory, so the casting body no changes. A major factor in the successful development of castings is the design of the die and design of gates, biscuit, and runner system. A well-designed gating and runner system should avoid turbulence in metal flow and to reduce incidence of inclusions and air entrapment in the casting. The die design is required to avoid solidification related defects like shrinkage, micro-porosities, hot-tear and so forth. Die design process is very much dependent on the experience and skill of the design engineer. The die for this study is the result of collaboration between the foundry factory and Department of Mechanical Engineering-National Kaohsiung University of Applied Sciences. The casting with full of the gating, runner system and biscuit, is shown in Figure 1. The die casting is designed in CATIA V5R19 software, shown in Figure 2. Moreover, the die casting material selection is very important. The nature of the material will directly affect the quality of the casting and die casting parameters configuration, this study selects casting material as the aluminium alloy
TABLE 1: Chemical composition of the alloy ADC10 used in the experiment.

\begin{tabular}{lcccccccc}
\hline Element & $\mathrm{Si}$ & $\mathrm{Fe}$ & $\mathrm{Cu}$ & $\mathrm{Mg}$ & $\mathrm{Mn}$ & $\mathrm{Ni}$ & $\mathrm{Zn}$ & $\mathrm{Sm}$ \\
\hline wt\% & $7.5 \sim 9.5$ & 1.3 & $3.0 \sim 4.0$ & 0.1 & 0.5 & 0.5 & 3 & 0.35 \\
\hline
\end{tabular}

ADC10. The chemical composition of the aluminum alloy used in the experimental procedure is given in Table 1.

Shrinkage porosity formation in pressure die casting is the result of a so much number of parameters. Figure 3 shows a cause and effect diagram that was constructed to identify the casting process parameters that may affect die casting porosity (Tsoukalas et al. 2004, 2008 [5, 6]). In this case, holding furnace temperature, die temperature, plunger velocity in the first stage, plunger velocity in the second stage, and multiplied pressure in the third stage were selected as the most critical in the experimental design. The other parameters were kept constant in the entire experimentation. The range of holding furnace temperature was selected as $640 \sim 700^{\circ} \mathrm{C}$, the range of die temperature as $180 \sim 260^{\circ} \mathrm{C}$, the range of plunger velocity in the first stage as $0.05 \sim 0.35 \mathrm{~m} / \mathrm{s}$ and in the second stage as $1.5 \sim 3.5 \mathrm{~m} / \mathrm{s}$, and the range of multiplied pressure in the third stage was chosen as 200 280 bars. The selected casting process parameters, along with its ranges, are given in Table 2.

Taguchi method based design of experiment has been used to study the effects of five casting process parameters (holding furnace temperature: $\mathrm{A}$, die temperature; $\mathrm{B}$, plunger velocity in the first stage; $C$, plunger velocity in the second stage; D, multiplied pressure in the third stage; $\mathrm{E}$, on an 


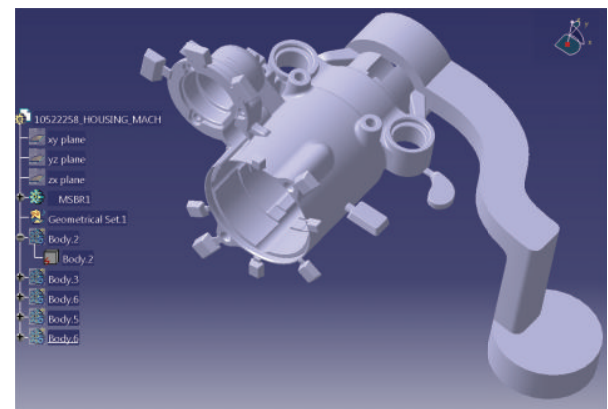

(a)

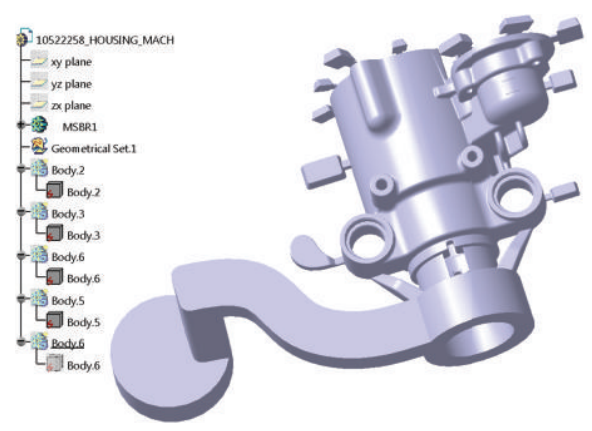

(c)

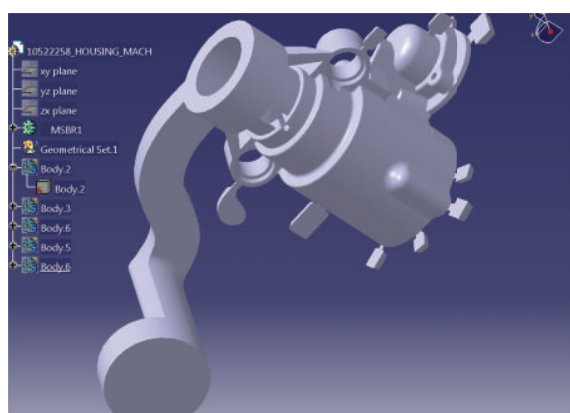

(b)

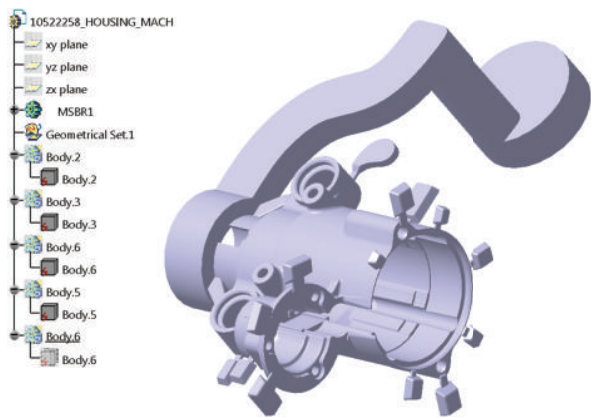

(d)

FIgUre 2: Part product is designed by CATIA software.
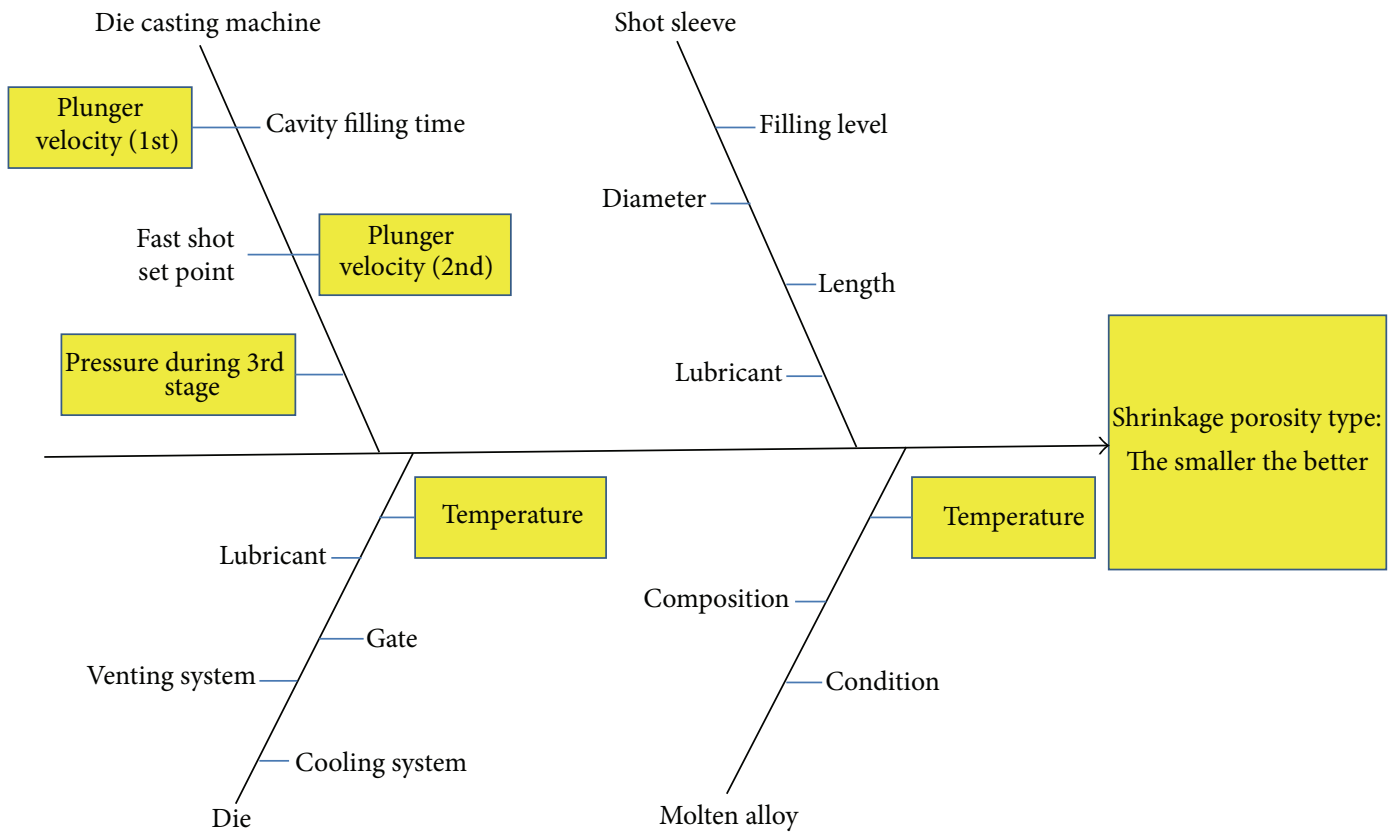

Figure 3: Cause and effect diagram.

TABLE 2: The parameter and its value at three levels.

\begin{tabular}{lcccc}
\hline Process parameters & Parameters range & Level 1 & Level 2 & Level 3 \\
\hline Holding furnace temperature $\left({ }^{\circ} \mathrm{C}\right)$ & $640 \sim 700$ & 640 & 670 & 700 \\
Die temperature $\left({ }^{\circ} \mathrm{C}\right)$ & $180 \sim 260$ & 180 & 220 & 260 \\
Plunger velocity, 1st stage $(\mathrm{m} / \mathrm{s})$ & $0.05 \sim 0.35$ & 0.05 & 0.2 & 0.35 \\
Plunger velocity, 2nd stage $(\mathrm{m} / \mathrm{s})$ & $1.5 \sim 3.5$ & 1.5 & 2.5 & 240 \\
Multiplied pressure (bars) & $200 \sim 280$ & & 3.5 \\
\hline
\end{tabular}


TABLE 3: Experimental layout using an $\mathrm{L}_{27}$ orthogonal array.

\begin{tabular}{|c|c|c|c|c|c|}
\hline Trials & $\begin{array}{c}\text { Holding furnace } \\
\text { temperature A }\end{array}$ & $\begin{array}{c}\text { Die temperature } \\
\text { B }\end{array}$ & $\begin{array}{c}\text { Plunger velocity 1st } \\
\text { stage C } \\
\end{array}$ & $\begin{array}{c}\text { Plunger velocity } 2 \text { nd } \\
\text { stage D }\end{array}$ & $\begin{array}{c}\text { Multiplied pressure } \\
\text { E }\end{array}$ \\
\hline 1 & 1 & 1 & 1 & 1 & 1 \\
\hline 2 & 1 & 1 & 2 & 2 & 2 \\
\hline 3 & 1 & 1 & 3 & 3 & 3 \\
\hline 4 & 1 & 2 & 1 & 2 & 2 \\
\hline 5 & 1 & 2 & 2 & 3 & 3 \\
\hline 6 & 1 & 2 & 3 & 1 & 1 \\
\hline 7 & 1 & 3 & 1 & 3 & 3 \\
\hline 8 & 1 & 3 & 2 & 1 & 1 \\
\hline 9 & 1 & 3 & 3 & 2 & 2 \\
\hline 10 & 2 & 1 & 1 & 2 & 3 \\
\hline 11 & 2 & 1 & 2 & 3 & 1 \\
\hline 12 & 2 & 1 & 3 & 1 & 2 \\
\hline 13 & 2 & 2 & 1 & 3 & 1 \\
\hline 14 & 2 & 2 & 2 & 1 & 2 \\
\hline 15 & 2 & 2 & 3 & 2 & 3 \\
\hline 16 & 2 & 3 & 1 & 1 & 2 \\
\hline 17 & 2 & 3 & 2 & 2 & 3 \\
\hline 18 & 2 & 3 & 3 & 3 & 1 \\
\hline 19 & 3 & 1 & 1 & 3 & 2 \\
\hline 20 & 3 & 1 & 2 & 1 & 3 \\
\hline 21 & 3 & 1 & 3 & 2 & 1 \\
\hline 22 & 3 & 2 & 1 & 1 & 3 \\
\hline 23 & 3 & 2 & 2 & 2 & 1 \\
\hline 24 & 3 & 2 & 3 & 3 & 2 \\
\hline 25 & 3 & 3 & 1 & 2 & 1 \\
\hline 26 & 3 & 3 & 2 & 3 & 2 \\
\hline 27 & 3 & 3 & 3 & 1 & 3 \\
\hline
\end{tabular}

important output parameter (Shrinkage porosity). For selecting appropriate orthogonal array, degree of freedom (number of fair and independent comparisons needed for optimization of process parameters is one less than the number of levels of parameter) of the array is calculated.

In the experimental layout plan with five factors and three levels using $\mathrm{L}_{27}$ orthogonal array, 27 experiments were carried out to study the effect of casting input parameters, shown in Table 3. The input parameters are installed in the ProCAST software to conduct 27 simulation experiments.

Computer simulation procedure-based process development and die design can be used for rapid process development and die design in a shorter time. Such a computer simulation based procedure, often using FINITE ELEMENT ANALYSIS based software systems, can improve the quality and enhance productivity of the enterprise by way of faster development of new product. Analysis software is used as a ProCAST commercial with finite element method analysis for a casting process. In this study, all parameters can be able to affect the analysis process, choice of material is aluminum alloy die casting ADC10, and cold chamber die casting method with molding material is H13. FEM based simulation software systems help the designer to visualize the metal flow in the die cavity, the temperature variation, the solidification progress, and the evolution of defects such as shrinkage porosity, cold-shut, hot-tear.

ProCAST a FEM simulation-based virtual casting environment for analysis of the casting process is used as a tool for die design and process optimization. ProCAST with VisualViewer module can provide temperature field, thermal cracking, flow field, solidification time, and shrinkage analysis. This paper focused on the analysis of shrinkage porosity by ProCAST software base on parameters input from Table 3.

The analysis of defects simulated by ProCAST software with Visual-Viewer module can detect many types of disabilities casting. The defective products do not necessarily reflect the loss of the original function, for example, the internal pore trims acceptable. However, with large structural castings, defect analysis of this study focuses on maximum porosity in the selection casting, and the important parts of the casting shrinkage analysis (an important component), casting defect analysis are described as follows. 


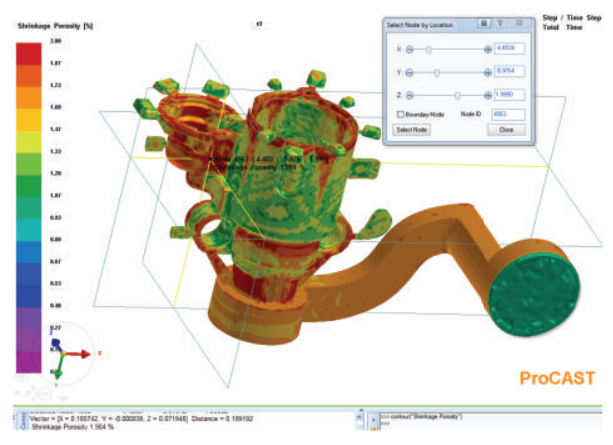

(a)

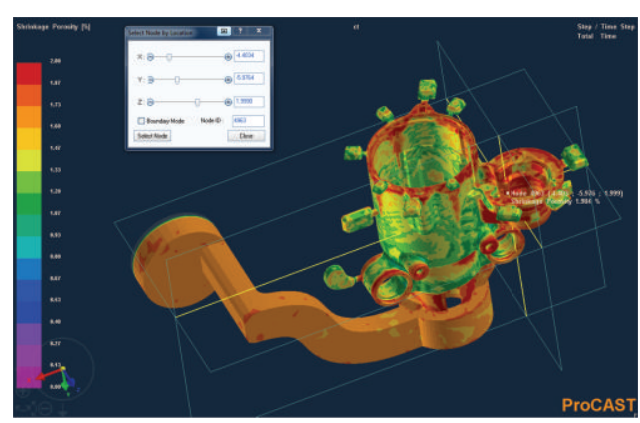

(c)

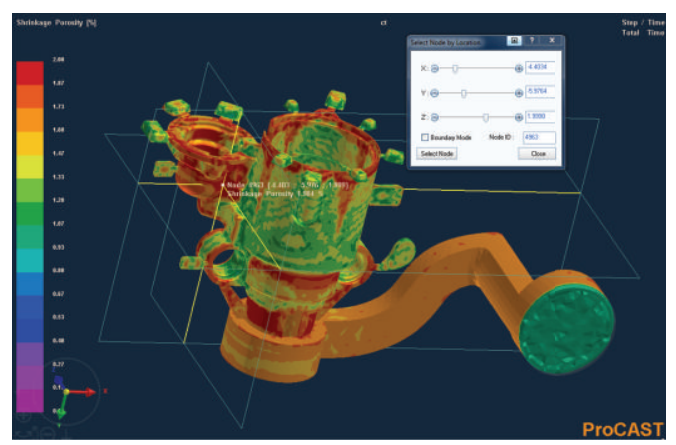

(b)

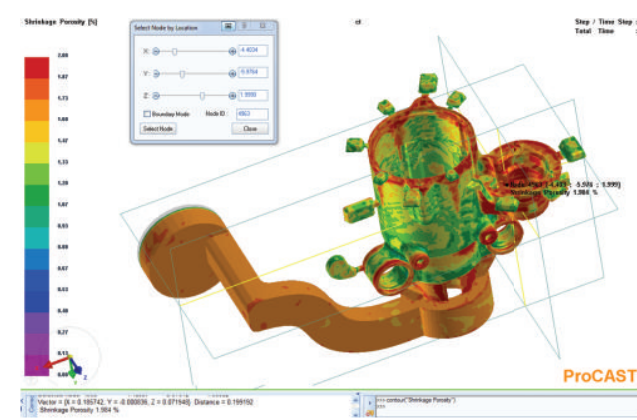

(d)

Figure 4: Casting measurement area.

The Solid Fraction. Solid fraction may be available shrinkage prediction casting position, the present study is in accordance with the theory prediction of defect, and ProCAST manual referred to in the final period of solidification. Shrinkage solid fraction prone is greater than 0.7 , here as the reference value of 0.7 solid fractions. When the solid fraction area is below this value and the area around the solid phase rate is rather than this value, we can predict this area shrinkage porosity occurred.

Maximum Porosity. The maximum porosity analysis using the Shrinkage Porosity function of the Visual-Viewer comes defined in the manual. According to the ProCAST user manual shrinkage definition and with the solid fraction, it can be used to analyse the basis of the maximum porosity.

Shrinkage Analysis. For the amount of inspection shrinkage casting part used for the Visual-Viewer module function for quantitative analysis. In each experiment we took five elements with the coordinates determined at the important positions in the working conditions of automobile starter motor casing. Each experiment was repeated five times in order to reduce experimental errors, as shown in Figure 4. Data from 27 experiments with five sampling times in each simulation are summarized as in Table 4. From this table, we conducted quality characteristics analysis.

Quality Characteristics. The parameter design study involves control and noise factors. The measure of interactions between these factors with regard to robustness is signal-tonoise $(S / N)$ ratio. $S / N$ characteristics formulated for three different categories are as follows: the bigger the better, and the smaller the better, the nominal the best. This paper focused on studying the effects of five input parameters $(A, B, C, D, E)$ to defect shrinkage porosity in the process of casting, so the criteria "the smaller the better" is selected.

The smaller the better (for making the system response as small as possible) is as follows:

$$
\frac{S}{N_{S}}=-10 \log \left(\frac{1}{n} \sum_{i=1}^{n} y_{i}^{2}\right),
$$

where $n$ is the number of sampling (Each experiment was repeated five times sampling, so that $n=5), y_{i}$ : value of Shrinkage porosity at each time sampling.

The responding graph shown in Figure 5 learned that the best combination for this study with shrinkage porosity defect value minimum is $A_{3} B_{3} C_{3} D_{1} E_{3}$.

Process Parameter Optimization Using MVLR. The objective of the process optimization is to select the optimal control variables in aluminium die casting process in order to obtain the minimum porosity. In this work, the fitness function used in the optimization procedure was based on the MVLR model.

Multivariable Linear Regression Analysis. In most cases, the form of the relationship between the response and the independent variables is usually unknown. Multiple linear regression (MLR) is a method used to model the linear relationship between a dependent variable and one or more 


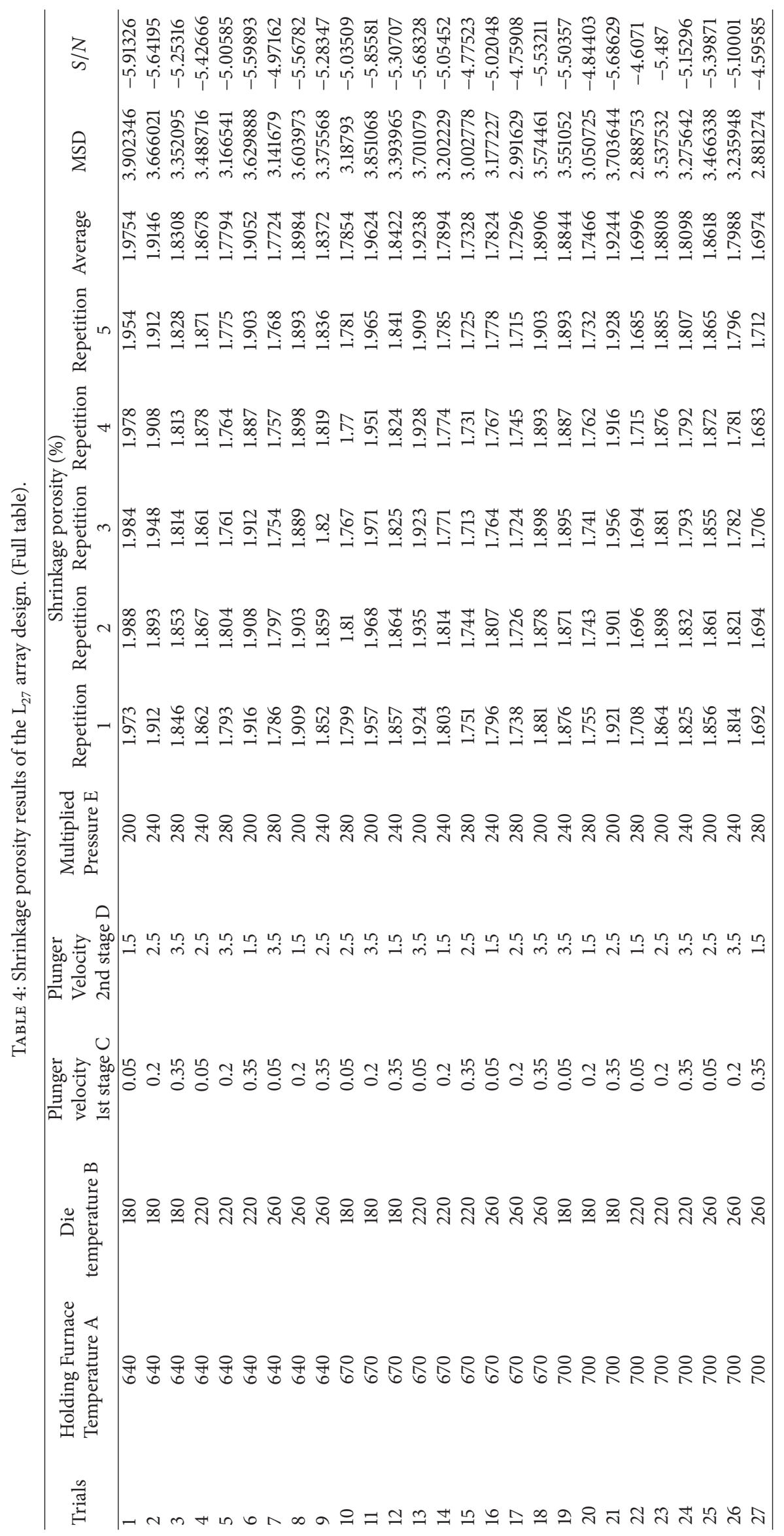


TABLE 5: The results after analysing by Intercooled Stada 8.2 software.

(a)

\begin{tabular}{|c|c|c|c|c|}
\hline \multicolumn{5}{|c|}{ reg Fx $A B C D E$} \\
\hline Source & SS & $\mathrm{df}$ & MS & $\begin{array}{c}\text { Number of obs }=27 \\
F(5,21)=146.74\end{array}$ \\
\hline Model & 0.155044498 & 5 & 0.0310089 & Prob $>F=0.0000$ \\
\hline Residual & 0.004437799 & 21 & 0.000211324 & $\begin{array}{c}R \text {-squared }=0.9722 \\
\text { Adj } R \text {-squared }=0.9655\end{array}$ \\
\hline Total & 0.159482297 & 26 & 0.006133935 & Root MSE $=0.01454$ \\
\hline
\end{tabular}

(b)

\begin{tabular}{lcccccc}
\hline Fx & Coef. & Std. Err. & $t$ & $P>|t|$ & \multicolumn{2}{c}{ [95\% Conf. Interval] } \\
\hline$A$ & -0.0008844 & 0.0001142 & -7.74 & 0.000 & -0.001122 & -0.0006469 \\
$B$ & -0.00083 & 0.0000857 & -9.69 & 0.000 & -0.0010081 & -0.0006519 \\
$C$ & -0.0305925 & 0.7284277 & -0.042 & 0.000 & -0.0780965 & 0.0169114 \\
$D$ & 0.0175444 & 0.0034264 & 5.12 & 0.000 & 0.0104189 & 0.02467 \\
$E$ & -0.0020122 & 0.0000857 & -23.49 & 0.000 & -0.0021904 & -0.0018341 \\
_cons & 3.054569 & 0.0820708 & 37.22 & 0.000 & 2.883893 & 3.225244 \\
\hline
\end{tabular}

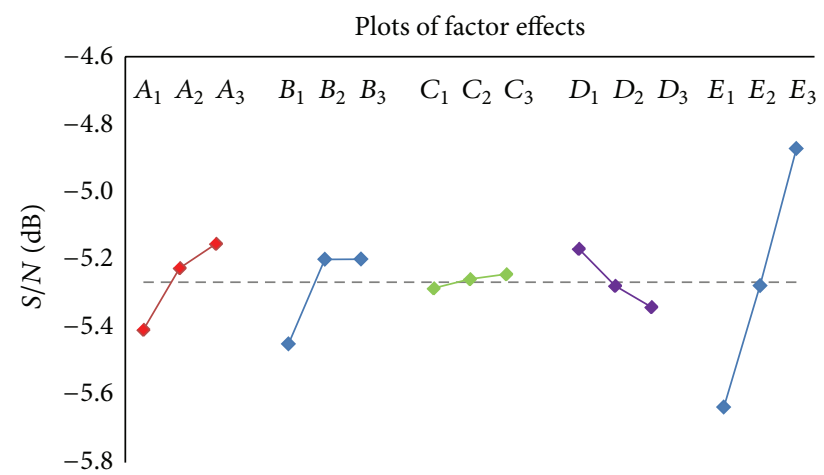

Figure 5: S/N Response graphs.

independent variables. MLR is based on least squares: the model is fitted such that the sum-of-squares of differences of observed and predicted values is minimized.

Let $x_{1} ; x_{2} ; \ldots ; x_{r}$ be a set of $r$ predictors believed to be related to a response variable $Y$. The linear regression model for the $j$ th sample unit has the form

$$
Y_{j}=\beta_{0}+\beta_{1} x_{j 1}+\beta_{2} x_{j 2}+\cdots+\beta_{r} x_{j r}+\varepsilon_{j},
$$

where $\varepsilon$ is a random error and the $\beta_{i}, i=0,1, \ldots, r$ are unknown regression coefficients.

In this paper, there are five independent variables and one dependent variable. The relationships between these variables are of the following form:

$$
F(x)=\beta_{0}+\beta_{1} A+\beta_{2} B+\beta_{3} C+\beta_{4} D+\beta_{5} E .
$$

In which

$F(x)$ : Dependence variable,

$A\left({ }^{\circ} \mathrm{C}\right)$ : Holding furnace temperature,
$B\left({ }^{\circ} \mathrm{C}\right)$ : Die temperature,

$C(\mathrm{~m} / \mathrm{s})$ : Plunger velocity 1 st stage,

$D(\mathrm{~m} / \mathrm{s})$ : Plunger velocity 2 nd stage,

$E$ (bars): Multiplied pressure during the third phase.

The results after analysing by Intercooled Stada 8.2 Softwere as shown in Table 5.

The final MVLR model equation for porosity after substituting regression coefficients is as follows:

$$
\begin{aligned}
F(x)= & 3.054569-0.8844 * 10^{-3} A-0.83 * 10^{-3} B \\
& -0.03059 C+0.01754 D-0.00201 E .
\end{aligned}
$$

\section{Results and Discussion}

We applied multivariable linear regression analysis (MVLR) to seek the optimal parameter in the casting process of independent parameter variables in this study. A stationary point for the optimal performance was obtained by using the multivariable linear regression method in this linear regression equation, and the result is presented in Figure 6. A very good fit was observed and substantiated by the coefficient of determination, $R^{2}=0.9722$. That is, the $R^{2}$ value indicates that the polynomial model explains almost $97.22 \%$ of variability in the casting process.

Figure 6 shows the efficacy of the optimization scheme by comparing the MVLR results with the experimental values. There is a convincing agreement between experimental values and predicted values for shrinkage porosity percent.

Matlab code for finding optimization shrinkage porosity value. 


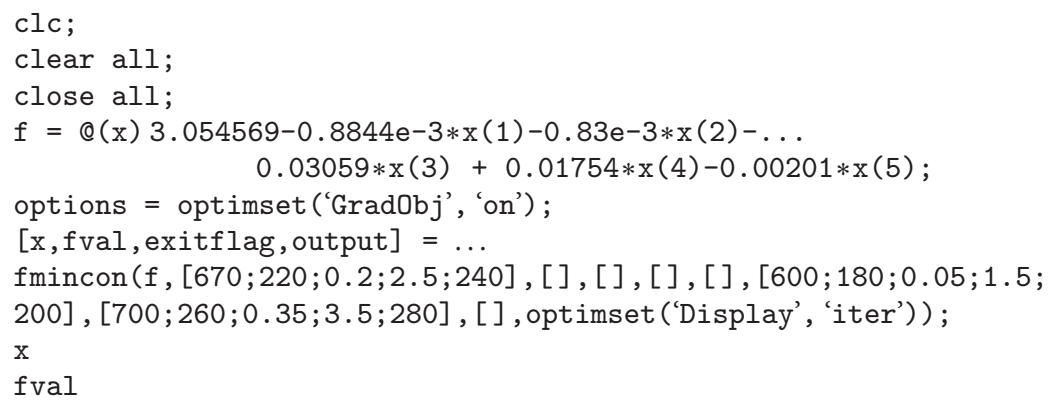

Algorithm 1

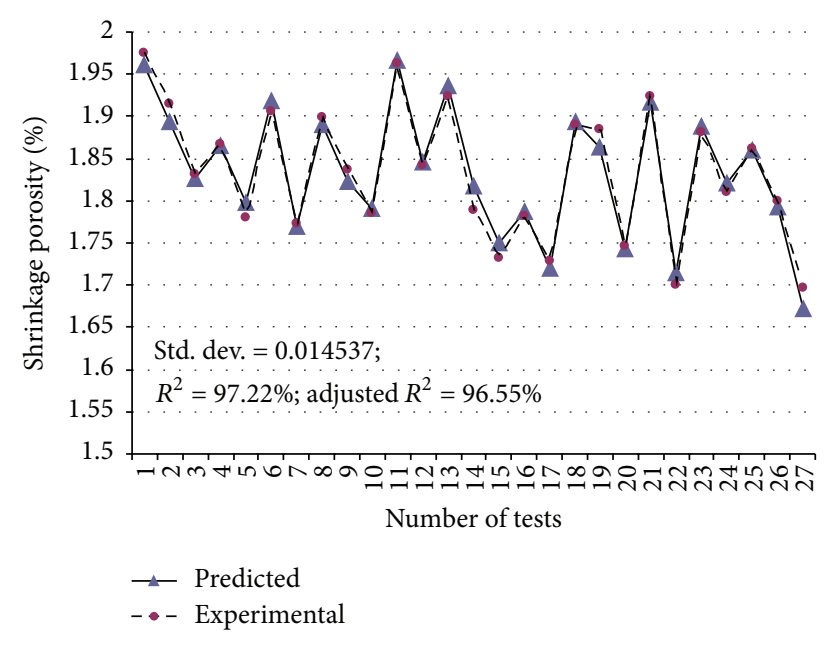

FIGURE 6: Experimental and predicted values of shrinkage porosity percent.

Program in Matlab (see Algorithm 1).

Results after running in Matlab are as follows:

$$
\begin{array}{cl}
x=700.0000 \quad \text { so that } \longrightarrow A & =700^{\circ} \mathrm{C} \\
260.0000 & B=260^{\circ} \mathrm{C} \\
0.3500 & C=0.35 \mathrm{~m} / \mathrm{s} \\
1.5000 & D=1.5 \mathrm{~m} / \mathrm{s} \\
280.0000 & E=280 \mathrm{bar}
\end{array}
$$$$
\text { fval }=1.6725 \quad \text { Shrinkage porosity }: 1.6725 \% \text {. }
$$

By the Program in Matlab, we are known as the best combination in the 27 experimental configurations.

This result is similar to quality characteristics and is the best combination for this study $A_{3} B_{3} C_{3} D_{1} E_{3}$.

\section{Conclusion}

In this paper, the optimum process parameters values predicted for casting of minimum shrinkage porosity
$(1.6725 \%)$ and the best combination parameters given as follows:

$$
\begin{aligned}
& \text { holding furnace temperature } 700^{\circ} \mathrm{C} \text {, } \\
& \text { die temperature } 260^{\circ} \mathrm{C} \text {, } \\
& \text { plunger velocity, 1st stage } 0.35 \mathrm{~m} / \mathrm{s} \text {, } \\
& \text { plunger velocity, } 2 \text { nd stage } 1.5 \mathrm{~m} / \mathrm{s} \text {, } \\
& \text { multiplied pressure } 280 \text { bar. }
\end{aligned}
$$

The model proposed in this paper gives satisfactory results in the optimization of pressure die casting process. The predicted values of the process parameters and the calculated are in convincing agreement with the experimental values.

The experiments which are conducted to determine the best levels are based on "Orthogonal Arrays," and are balanced with respect to all control factors and yet are minimum in number. This in turn implies that the resources (materials, saving time, and money) required for the experiments are also minimized.

\section{References}

[1] C. Shen, L. Wang, and Q. Li, "Optimization of injection molding process parameters using combination of artificial neural network and genetic algorithm method," Journal of Materials Processing Technology, vol. 183, no. 2-3, pp. 412-418, 2007.

[2] M. S. Dargusch, G. Dour, N. Schauer, C. M. Dinnis, and G. Savage, "The influence of pressure during solidification of high pressure die cast aluminium telecommunications components," Journal of Materials Processing Technology, vol. 180, no. 1-3, pp. 37-43, 2006.

[3] G. O. Verran, R. P. K. Mendes, and M. A. Rossi, "Influence of injection parameters on defects formation in die casting Al12Si1,3Cu alloy: experimental results and numeric simulation," Journal of Materials Processing Technology, vol. 179, no. 13, pp. 190-195, 2006.

[4] S. H. Mousavi Anijdan, A. Bahrami, H. R. Madaah Hosseini, and A. Shafyei, "Using genetic algorithm and artificial neural network analyses to design an Al-Si casting alloy of minimum porosity," Materials and Design, vol. 27, no. 7, pp. 605-609, 2006.

[5] V. D. Tsoukalas, S. A. Mavrommatis, N. G. Orfanoudakis, and A. K. Baldoukas, "A study of porosity formation in pressure die casting using the Taguchi approach," Journal of Engineering Manufacture, vol. 218, no. 1, pp. 77-86, 2004. 
[6] V. D. Tsoukalas, "Optimization of porosity formation in $\mathrm{AlSi}_{9} \mathrm{Cu}_{3}$ pressure die castings using genetic algorithm analysis," Materials and Design, vol. 29, no. 10, pp. 2027-2033, 2008.

[7] G. P. Syrcos, "Die casting process optimization using Taguchi methods," Journal of Materials Processing Technology, vol. 135, no. 1, pp. 68-74, 2003.

[8] G. Taguchi, Introduction to Quality Engineering, Asian Productivity Organization, UNIPUB, 1986. 


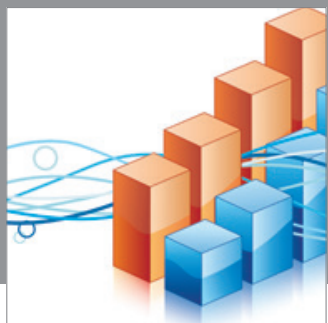

Advances in

Operations Research

mansans

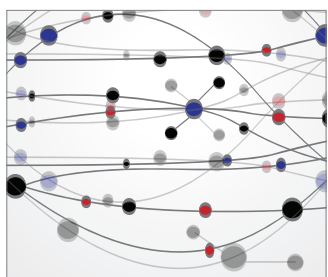

The Scientific World Journal
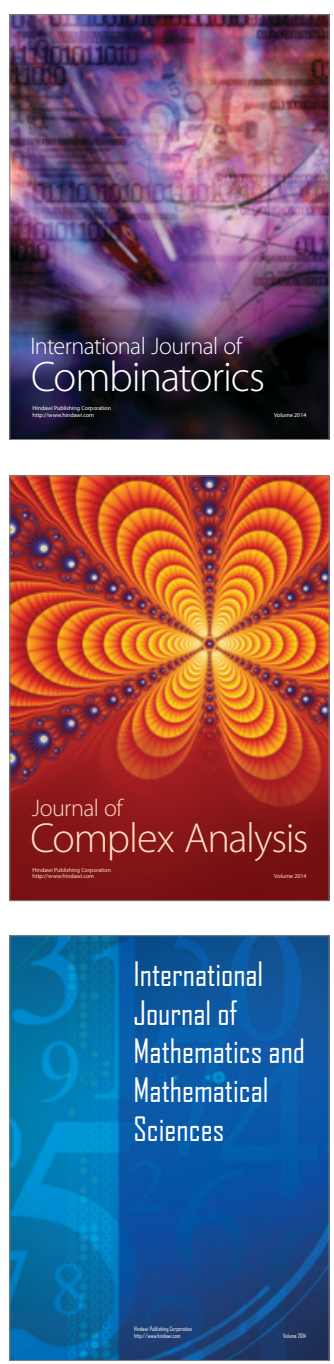
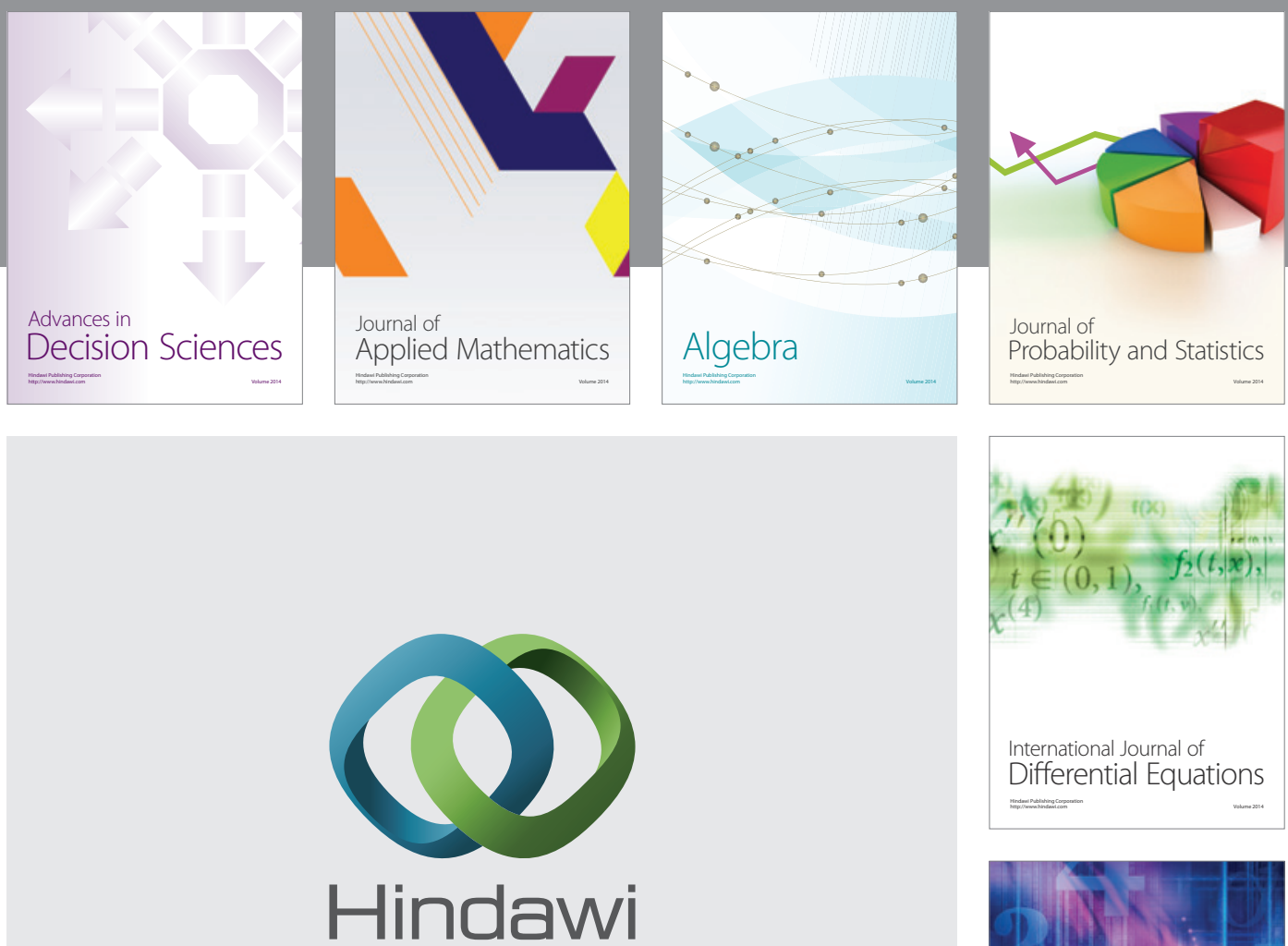

Submit your manuscripts at http://www.hindawi.com
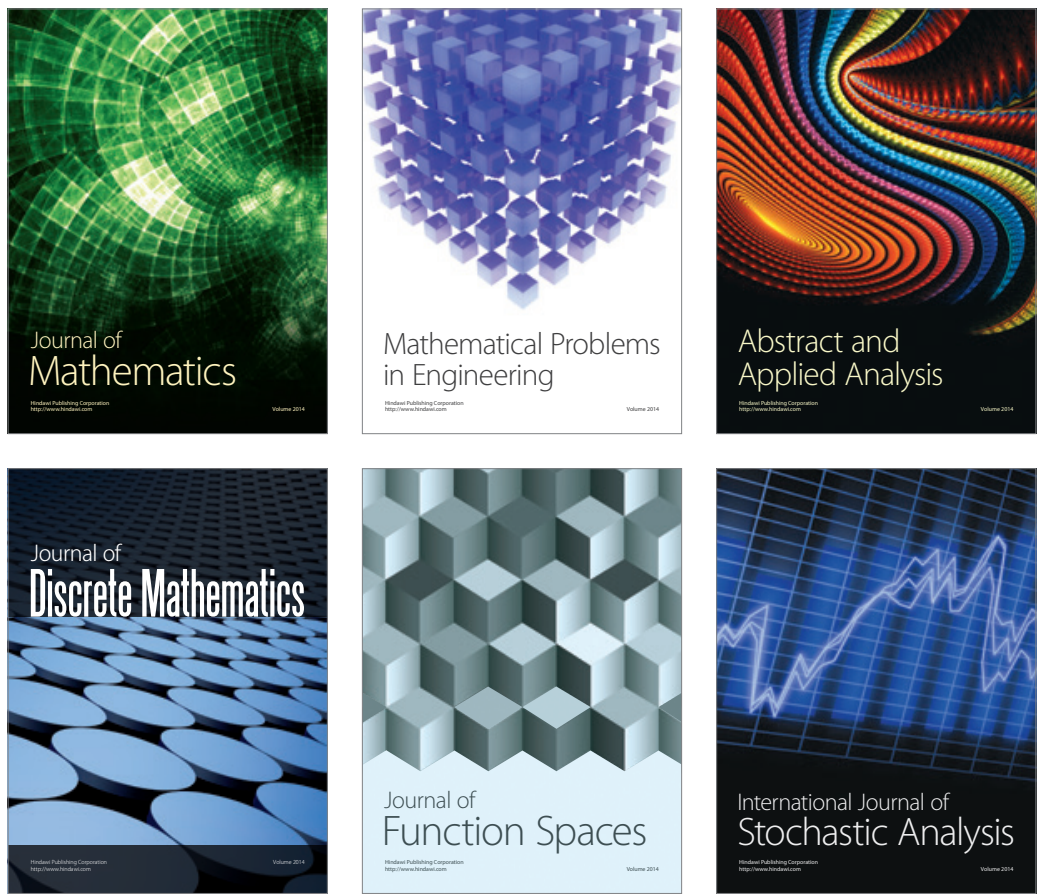

Journal of

Function Spaces

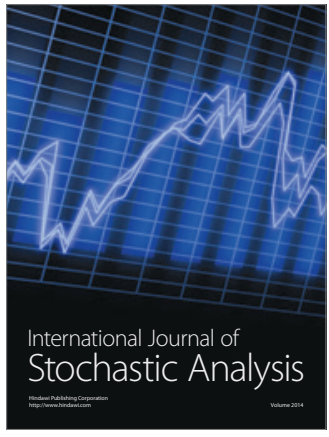

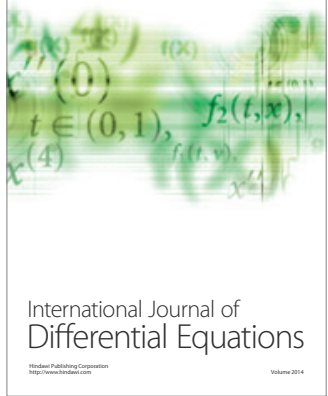
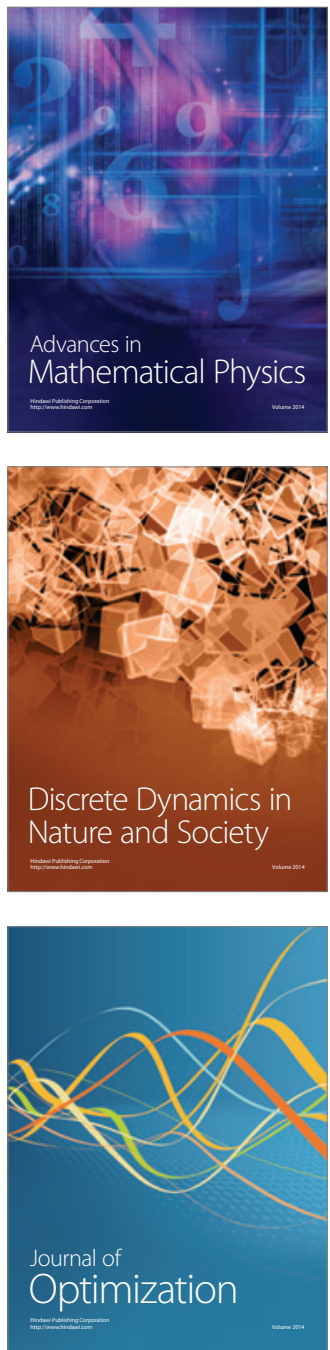